Short Communication

\title{
THE MODEL OF FITNESS IN A HETEROGENEOUS ENVIRONMENT ON REACTION NORMS
}

\author{
Volodymyr Gerasymenko \\ Odessa State Agrarian University, 13 Panteleimonivska Str., Odessa, 65012, UKRAINE \\ gerasym08@ hotmail.com
}

\begin{abstract}
The understanding of genetic mechanisms of natural selection to a large extent became possible as a result of modelling research carried out in the fields of evolutionary and population genetics. However, genetic models cannot be considered exhaustive in the description of natural selection because a phenotype of individual, environment and fitness remains beyond their framework. Consequently, the value of fitness is not derived from the algorithmic model but arbitrarily assigned by a researcher to genotypes in their genetic formula. This work proposes a model of genotype fitness in heterogeneous environments on reaction norms in connection with the genetic structure of the population. Two equations represent the model. The first is an incomplete second order polynomial that describes the dependence of fitness on the phenotype of an adaptive trait and environmental conditions. The second is a linear equation of the reaction norm of the adaptive trait that determines its phenotype in specific environmental conditions. According to the model algorithms, rating of fitness in the population, and, consequently, their probability of selection, is determined by phenotype optimality and their norm of reaction in certain environmental conditions.
\end{abstract}

Key words: natural selection, adaptation, fitness function, environmental conditions, genotypeenvironment interaction.

Wide modelling investigations in evolution and population genetics to a large extent have determined the understanding of genetic mechanisms of natural selection. Nevertheless, from the description of natural selection in the synthetic theory, the genetic models cannot be considered to be exhaustive, because the phenotype of the individual, the environment, and fitness remain beyond their frameworks. As per Schmalhausen, natural selection, i.e. survivability of the fittest, is a positive estimation of the phenotype. However, the phenotype reflects properties of a genotype in known conditions of development of the individual. Thus, together with phenotypes, the corresponding genotypes are selected. As a result, reproduction of some phenotypes-genotypes dominate and replace the others, resulting in changes of the population structure (Schmalhausen, 1968). In this conceptual model fitness plays crucial significance, and, only as a result of genotype differences by this characteristic, differentiated survival of individuals in generations is provided. However, in genetic models of natural selection that have been explained by the Hardy-Weinberg law, the phenotype of the individual and the environment are left beyond its framework. Consequently, the value of fitness is not the result of the algorithmic model, but the value arbitrarily assigned by the researcher to the genotype with the corresponding genetic formula, that finally defines the genetic structure of a theoretical population.
There exist several models of fitness in heterogeneous conditions of the environment. Research in this area was introduced by Levins (1962). Later two types of models were developed: mechanistic model of ecological niche in which fitness is connected with functional traits of an organism (Crozier and Dwyer, 2006; Buckley, 2010; Kearney, 2010), and the models in which fitness is connected with the norm of reaction (Gavrilets and Scheiner, 1993; Gabriel, 2005; Chevin, 2010; Chevin, 2013). The proposed models differ both by the assumptions put in them and by the form and essence of the target algorithms characterising fitness. In this work, we develop a model of fitness of population genotypes on reaction norms in a heterogeneous environment in accordance with concepts of natural selection in evolution theory.

The synthetic theory of evolution considers fitness as a result of the direct interaction of the phenotype with environmental conditions. Thus, fitness is expressed by the concordance of an organism's structure and functions to normal vital conditions surrounding it and reached by contrivance or adaptations, which always mean the quite specific design of the body (and an organism) in connection with the given conditions of the environment (Schmalhausen, 1968). Therefore, it is possible to speak about the functional interrelation of genotype fitness with the degree of conformity of 
the adaptive trait genotype to the environmental conditions: the higher it is, the higher the genotype fitness. Thus, fitness of genotype in the population can be expressed by the function $(F)$ of environment conditions and the phenotype of the adaptive trait of the same genotype:

$w_{i j l}=F\left(e_{j}, p_{i l}\right)$,

where $w$ - relative fitness, which shows the relative efficiency of reproduction of genotypes in a population; $e-$ environment conditions, represented by the specific factor; $p-$ phenotype of the adaptive trait, which is a value of any trait in the specific environment conditions, associated with fitness; $i$ - population genotypes: $1,2,3 \ldots i \ldots n ; j$ - a gradient of environment conditions: $1,2,3 \ldots j \ldots m ; l$-values of phenotypes of the adaptive trait: $1,2,3 \ldots l \ldots m l$.

The phenotype of the individual, in turn, is a realisation of the norm of reaction of a genotype in specific conditions of the environment (Schmalhausen, 1968). In this respect, the norm of reaction is the function of the phenotype of the $i$-th genotype from conditions of the environment (De Jong, 1990; Weiss and Gorman, 1990; Chevin et al., 2010). Thus, the value of the phenotype of $i$-th genotype of the same $j$-s conditions of the environment expression (1) will look like:

$p_{i j}=G_{i}\left(e_{j}\right)$.

The index $i$ at $G$ specifies genetic specificity of the function parameters. After replacing $p_{i j}$ in the equation (1) on $G_{i}\left(e_{j}\right)$ from the equation (2) the function of fitness becomes:

$w_{i j l}=F\left(e_{j}, G_{i}\left(e_{j}\right)\right)$.

This expression shows that fitness is the function of environment conditions and reaction norm of the adaptive trait. Also, from this it follows that fitness and the phenotype of the adaptive trait are determined by the general conditions of the environment. This quite corresponds to Scheiner Samuel statement that environment plays two roles in the evolutionary process. First, environment establishes the relationship between the phenotype of an individual and fitness, the fitness function. Second, the environment interacts with the developmental process and plays a role in determining the phenotype (Scheiner, 1993).

Values of fitness by an ecological gradient and norms of reaction are defined by a certain kind of functions in equations (1) and (2). The description of fitness level as degrees of conformity of the individual phenotype to conditions of the environment assumes the presence of an optimum of the function $F$ for independent variables: of the environment conditions and the phenotype of the adaptive trait. Such function for one genotype (g) graphically can be presented as a bell-shaped curve (Fig. 1). In quantitative genetic terminology, this curve describes the phenotypic dependence of fitness on conditions of the environment on an axis $\mathbf{e}$ and values of phenotypes on an axis p. According to the tolerance curve, fitness of a genotype $\mathbf{g}$ reaches maximum only at an optimal expression of the environment conditions opt e and phenotype of the adaptive trait opt p. Under such cir-

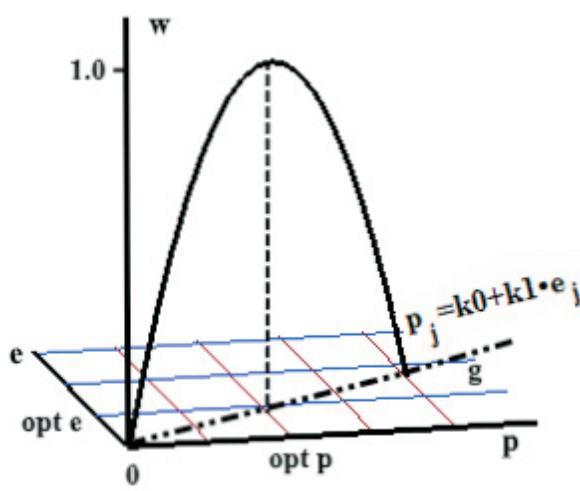

Fig. 1. Dependence of fitness (w) from the phenotype of the adaptive trait (p) of hypothetical genotype (g) and environmental conditions (e), where, $p_{j}=k 0+k 1 \cdot e_{j}$ is the adaptive trait of the reaction norm; $k 0$ and $k 1$ are coefficients of the linear equation of the norm of reaction. Coordinate axis: $\mathrm{p}-$ phenotype of the adaptive trait values, $\mathrm{e}-$ the value of environmental conditions, w - relative fitness.

cumstances, the expression of the phenotype of a certain genotype $\mathbf{g}$ fitness function is ideal, and reflects the maximum fitness for its genotype. The value of the phenotype of the individual is defined by its norm of reaction in the same conditions of the environment as the fitness. It is estimated that the reaction norms can be both linear and nonlinear. However, as a rule, the linear equations for norms of reaction are used in the models (Weiss and Gorman, 1990; Chevin et al., 2010). Besides, the symmetric form of the tolerance curve assumes linear norm of reaction of the adaptive trait: $p_{j}=k 0+k l \cdot e_{j}$. The deviation of conditions of the environment from an optimum modifies the phenotype of the adaptive trait according to its norm of reaction and shifts its value from an optimum. It reduces its fitness function and, finally, fitness itself to its complete loss. In this connection, it is possible to say that the reaction norm of the adaptive trait is limited by its fitness. On the graph, this area is in the area of the crossing of fitness curve with a line of the norm of reaction. Restoration of phenotype fitness function in changed conditions of environment is possible only when its value will come back to the optimum. It is possible in two cases: if conditions of the environment come back to optimum values for the genotype $\mathbf{g}$ or if in there will be another genotype population, which realises an optimum phenotype in the new optimum for its conditions. Hence, to keep the value of fitness function the value of adaptive phenotype should have an optimum expression for genotypes in various conditions of the environment.

In general, the function of two variables, in our case, the environment conditions and the phenotype of an adaptive trait, in graphic form is a surface. The tolerance curve of the genotype (Fig. 1) is located on this surface. Its graph denotes the parabolic type of the surface. So, based on the graph of the function we can define its equation. Based on these reasons, the most suitable equation of the function of fitness of the individual in a population $\left(w_{i j l}\right)$ depending on conditions of the environment $\left(e_{j}\right)$ and the phenotype $\left(p_{l}\right)$ in expression (1) can be an incomplete second order polynomial in which 


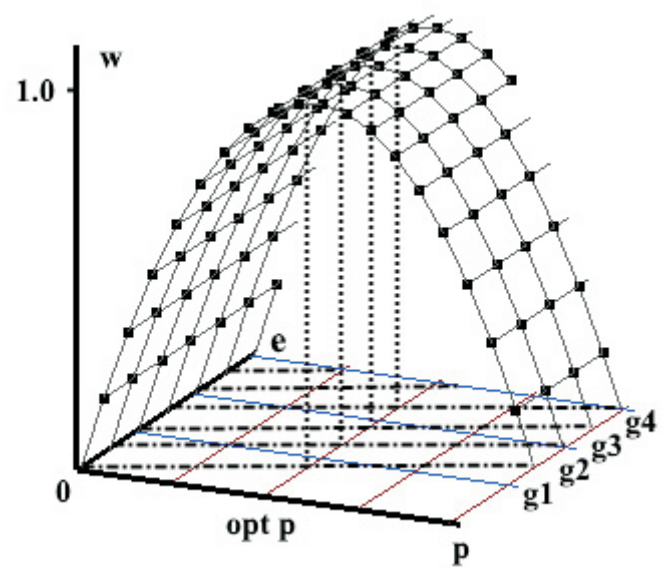

Fig. 2. Fitness of four hypothetical genotypes (g1, g2, g3 and g4) on norms of reactions in a heterogeneous environment.

values of fitness of $i$-th genotype on the parabolic surface are defined as:

$w_{i j l}=b 0+b 1 p_{l}+b 2 e_{j}+b 3 p_{l}^{2}$,

where $b 0-$ intercept coefficient, which is equal $w$ at $p=0$ and $e=0 ; b 1$ - linear coefficient of the factor $p ; b 2$ - linear coefficient of the factor $e ; b 3$ - second-degree coefficient of the factor $p . b 1, b 2$, and $b 3$ are coefficients that show the change $w$ at changing of the independent variable by 1 and the constant value of variables at other coefficients.

Thereafter, phenotype of the adaptive trait for certain genotype is determined by linear equation of reaction norm:

$p_{i j}=k O_{i}+k l e_{j}$,

where $k 0$ - intercept coefficient, $k l$ - linear coefficient.

Equations (4) and (5) together represent the fitness model of the population genotype based on the ecological gradient and reaction norms. The graph (Fig. 2) represents fitness that was simulated with use of the given algorithms for four genotypes (g1, g2, g3 and $\mathbf{g 4}$ ) of the adaptive trait in a range of environment conditions. According to the model conditions, the optimum value of the phenotypes is identical to all genotypes of the population. However, every genotype has its optimum of the environment. g1, g2, g3 and g4 genotypes that can be represented by different genetic formulas, for example, AA, Aa, aa, the range of multiple alleles and multilocus formulas. The coefficient of selection $\mathrm{s}=1-$ $\mathrm{w}$ is certainly related to fitness and describes the rate of the decrease of genotypes in a population and its genetic structure in each generation. Fitness is related to the coefficient of selection as $\mathrm{s}=1-\mathrm{w}$, which determines the speed of genotype decrease in the population and the population genetic structure in each generation.

From equation 4 of the model it follows that under specific environmental conditions the dependence of the adaptability of genotypes on the adaptive trait is described by a parabola. In this case, the values of the environment conditions $\boldsymbol{e}$ in the equation (4) for all genotypes at $j=$ const are similar and equals $e_{\text {const }}$. Accordingly, the equation $b 2 \mathrm{e}_{\text {const }}$ for certain environment conditions equals constant value $C$. Therefore, the equation (6) became the parabola equation:

$w_{i j}=b 0+b 1 p_{l}+b 3 p_{l}^{2}+C$.

Because the environment conditions are the same for all genotypes, then using quantitative genetic terminology, which determines phenotype value of the individual as a sum of contributions of genotype and environment $(p=g+e)$, the value of environmental component $e$ equals zero and the phenotype value of trait equals to genotype value: $p=g$. In this case, it is possible to talk about genotypic of fitness from phenotype-genotype of the adaptive trait dependence. A researcher can observe this relationship in an experiment of fitness to adaptive trait dependence in certain environment conditions: year, geographical position.

Thus, the proposed model of population genotypes fitness in heterogeneous environment conditions is a logical link in a formalisation of the natural selection principles of the synthetic theory of evolution. The model is presented by two equations. The first is incomplete two-factorial polynomial, which describes fitness depending on phenotypes of the adaptive trait and the conditions of the environment. The second represents the linear regression equation - the realisation of phenotypes on norms of reaction.

The model defines a size of fitness of genotypes in a population, and, accordingly, the probability of their selection based on the level of an optimality of their phenotypes and their norms of reaction to the environment conditions. In this way, the algorithms realise the mechanism of selection of genotypes based on norms of reactions in connection with fitness. Objectivity of the model is proven to be true by correspondence of its principles to the evolutionary theory principles.

We believe that the model of the genotypes fitness in a population can be used for the development of models of adaptation in extreme conditions of environment, for example, in connection with climate change, ecological niche models, breeding modelling for productivity of the agricultural plants and animal, and other directions connected with fitness.

\section{ACKNOWLEDGMENTS}

I thank Iryna Guzhva for assistance in writing this article.

\section{REFERENCES}

Buckley, L. B., Urban, M. C., Angilletta, M. J., Crozier, L. G., Rissler, L. J., Sears, M. W. (2010). Can mechanism inform species' distribution models? Ecol. Lett., 13 (8), 1041-1054.

Chevin, L.-M., Gallet, R., Gomulkiewicz, R., Holt, R. D., Fellous, S. (2013) Phenotypic plasticity in evolutionary rescue experiments. Philos.Trans. Royal Soc. B: Biol. Sci., 368 (1610), 1-12.

Chevin, L.-M., Lande, R., Mace, G. M. (2010). Adaptation, plasticity, and extinction in a changing environment: Towards a predictive theory. PLoS Biol, 8 (4), 1-8. 
Crozier, L., Dwyer, G. (2006). Combining population-dynamic and ecophysiological models to predict climate induced insect range shifts. Amer. Natur., 167 (7), 853-866.

De Jong, G. (1990). Quantitative genetics of reaction norms. J. Evol. Biol., 3 (5-6), 447-468.

Gabriel, W., Luttbeg, B. A. S., Tollrian, R. (2005). Environmental tolerance, heterogeneity, and the evolution of reversible plastic responses. Amer. Natur., 166 (3), 339-353.

Gavrilets, S., Scheiner, S. M. (1993). The genetics of phenotypic plasticity. VI. Theoretical predictions for directional selection. J. Evol. Biol., 6 (1), 49-68.
Kearney, M., Simpson, S. J., Raubenheimer, D., Helmuth, B. (2010). Modelling the ecological niche from functional traits. Philos. Trans.: Biol. Sci., 365 (1557), 3469-3483.

Levins, R. (1962). Theory of fitness in a heterogeneous environment. I. The fitness set and adaptive function. Amer. Natur., 96 (891), 361-373.

Scheiner, S. M. (1993). Genetics and evolution of phenotypic plasticity. Annu. Rev. Ecol. Syst., 49, 35-68.

Schmalhausen, I. I. (1968). Factors of Evolution: The Theory of Stabilizing Selection. [Шмальгаузен, И. И. Факторы эволюиии: Теория стабилизирующего отбора]. Nauka, Moscow. 451 pp. (in Russian).

Weiss, A., Gorman, W. (1990). Measuring selection on reaction norms: An exploration of the Eurosta-solidago System. Evolution, 44 (4), 820-831.

\section{PIELĀGOTİBAS MODELIS GADĪJUMĀ AR ATŠK̦IRĪGĀM REAKCIJAS NORMĀM UZ ĀRĒJĀS VIDES APSTĀKḶIEM}

Izstrādāts matemātiskais modelis, kurš apraksta pielāgotības atkarību no atškirīgām reakcijas normām uz ārējās vides apstākḷiem saistībā ar populācijas ğenētisko struktūru. 